\title{
A disciplina escolar na década de 1940: aspectos da interdependência entre Escola e Estado
}

\begin{abstract}
Resumo: Analisaram-se as práticas disciplinares presentes no artigo "O problema da disciplina" publicado na Revista do Ensino, na década de 1940, à luz da Teoria dos Processos de Norbert Elias. Trata-se de um estudo com abordagem qualitativa realizado por meio de uma análise documental. Fez-se uma breve discussão acerca das mudanças de conduta docente em relação ao comportamento discente: dos castigos físicos às estratégias de persuasão, por meio das estratégias disciplinares. Compreendeu-se a referida revista como uma pedagogia cultural, tendo-se em vista que educava docentes daquela época e contexto. A análise ora desenvolvida à luz da Teoria Eliasiana permitiu vislumbrar as práticas e os jogos de poder que circundam a figuração professor-aluno e, principalmente, o compromisso da educação escolar com o Estado na formação de cidadãs e cidadãos civilizados. Castigando ou persuadindo, o foco continuou sendo o professor e sua prática pedagógica, principalmente, no que diz respeito à regulação do comportamento das crianças.
\end{abstract}

Palavras-chave: Educação. Práticas disciplinares. Teoria dos Processos. Figuração professor-aluno.

\section{Introdução}

A escola é um ambiente de socialização onde somos educados, ensinados ou civilizados para viver em sociedade. (ELIAS, 2008) Para esse fim, as práticas que compõem o ambiente escolar são ditas como pedagógicas, assim como as relações que nela se estabelecem. (VICENT; LAHIRE; THIN, 2001)

Dentro das relações pedagógicas (relações sociais), o relacionamento professor-aluno é modificado ao longo do tempo de acordo com uma série de fatores, dentre eles os culturais e sociais. Fazendo-se um paralelo com a Teoria dos Processos de Norbert Elias (1990), pode-se dizer que o relacionamento professor-aluno é uma configuração, em que os envolvidos se interdependem, exercendo mutuamente uma função social. Sendo assim, tanto professor(a) como estudante, possuem oportunidades de poder distintas. Nesse artigo, enfoca-se o poder que os professores exercem sobre os alunos, por meio de práticas disciplinares.

Dentro das relações pedagógicas "educar" os corpos das crianças para a vida social significou durante muito tempo o exercício da punição, mais especificamente, com uso do castigo físico ou moral. Desde o início do processo de escolarização, a escola tinha
Bruna Kedman Nascimento de Souza Leão

Universidade Federal da Paraíba (UFPB)

brunakedmanl@gmail.com

Ricardo de Figueiredo Lucena Universidade Federal da Paraíba (UFPB)

cacolucena@gmail.com 
o consentimento das famílias para utilização dos castigos físicos, pois estes eram revestidos de uma intencionalidade educativa.

Castigar o corpo no ambiente escolar foi uma prática que persistiu até o início da primeira metade do século XX, sendo diretamente relacionada à Escola Tradicional. Contrários a isso, os pressupostos da Escola Nova sugerem o uso da disciplina como ferramenta mais adequada à educação (regulação) dos sujeitos, sem o uso da humilhação ou sofrimento, visto que naquele momento o aluno tornou-se o foco do processo de ensino-aprendizagem. (SOUZA, 2003)

A disseminação dos pressupostos da nova educação intuía reformar não apenas a escola, mas a sociedade em sua totalidade, sendo transmitida por diversos meios de comunicação como o rádio, o cinema e as revistas. Sob a ótica dos Estudos Culturais da Educação, esses meios podem ser classificados como pedagogias culturais, por serem dispositivos que transmitem valores e atitudes mesmo sem explicitarem suas intenções, ou seja, são um tipo de pedagogia porque educam, estando diretamente atrelados às relações de poder, caracterizadas pela força coercitiva entre os envolvidos. (WORTMAN; COSTA; SILVEIRA, 2015)

No contexto da Parahyba do Norte, no atual estado da Paraíba, foi criada a Revista do Ensino, um impresso pedagógico trimestral voltado para a formação de professores da educação primária. O primeiro volume da revista foi publicado em 1932 e, o último, dez anos depois, em 1942. A revista servia como uma espécie de manual acerca de como proceder de acordo com a Educação Nova, além de divulgar a nova cultura educacional e social por meio de artigos. (ASSUNÇÃO, 2016)

Neste trabalho, analisou-se o artigo "O problema da disciplina", presente na revista $n^{0} 18$, publicada em 1942, à luz da teoria de Norbert Elias. A escolha daquele artigo possibilitou vislumbrar as relações de poder que circundavam, e ainda circundam, o ambiente escolar e, principalmente, a interconexão escola-Estado, permitindo-nos refletir acerca das práticas disciplinares na década de 40 como construtos que tinham um compromisso direto com os interesses do Estado, em sua plena reforma e progresso. Trata-se, portanto, de uma pesquisa de abordagem qualitativa realizada por meio de uma análise documental.

O artigo será organizado da seguinte maneira: na primeira seção apresenta-se uma breve aproximação teórica acerca das relações 
de poder no ambiente escolar a partir da teoria de Norbert Elias, dialogando com outros autores; na seção seguinte, situa-se o contexto histórico no qual a Revista do Ensino foi criada, assim como sua caracterização e objetivos, seguida da análise do artigo "O problema da disciplina". Por último, são realizadas as considerações acerca do que fora discorrido, evidenciando-se a importância de pensar a indissociabilidade das práticas escolares e relações pedagógicas com os contextos sociais e culturais nos quais elas estão inseridas.

\section{Jogos de poder no ambiente escolar: contribuições de Norbert Elias}

Norbert Elias foi um sociólogo que não debruçou seus estudos especificamente para o campo da Educação, no entanto, os conceitos construídos por ele podem contribuir para a leitura e interpretação das práticas que constituem e circundam o ambiente escolar. Para Elias (1990) indivíduo e sociedade são categorias indissociáveis, ou seja, as estruturas social e individual constroem-se e modificam-se de forma mútua, interdependente. Desse modo, a sociedade é uma grande figuração: grupo de pessoas mutuamente dependentes e orientadas, constituída por vários outros grupos ou figurações menores, formando uma grande teia de interdependência.

De acordo com a Teoria Eliasiana, o poder permeia todas as relações sociais. (ELIAS, 2008) Essa relação de dominação é "[...] caracterizada por uma distribuição das 'oportunidades de poder' claramente desigual" (ELIAS, 2012, p. 471) entre os envolvidos. Elias substitui o termo relações de poder por jogos de poder, especificamente na obra Introdução à Sociologia, na qual ele descreve modelos de jogos de poder. A utilização dessa terminologia pressupõe a competição e a arbitrariedade exercidas pelos indivíduos. (ELIAS, 2008)

Nesse sentido, todos os envolvidos numa relação social possuem diferentes oportunidades ou gradientes de poder: maiores ou menores a depender das situações relacionais. É o desequilíbrio ou desigualdade dessas oportunidades, ou seja, a balança ora pende para um lado ora para outro, que consiste o equilíbrio das relações, não a igualdade.

A relação pedagógica professor-aluno é também um jogo de poder em que as oportunidades são desiguais. Vale salientar que os envolvidos têm suas ações norteadas por fatores que muitas 
vezes extrapolam os muros da escola, visto que a educação formal tem compromisso direto com os interesses de uma estrutura social maior, atendendo a um projeto civilizatório. Assim, a intenção pedagógica do professor está atrelada a determinados interesses.

Nesse estudo, enfoca-se o interesse do Estado em construir uma sociedade homogeneizada. Professores, estudantes e Estado fazem parte de uma grande teia de interdependências: as ações dos sujeitos não são isoladas, mas estão relacionadas à estrutura social, às circunstâncias e às configurações que as pessoas formam umas com as outras. Segundo Elias (2012, p. 486), essas interdependências fazem parte de um modelo processual que contém "[...] um movimento dialético entre mudanças sociais intencionais e não intencionais".

Por esse viés, a disciplinarização de comportamentos é uma estratégia pedagógica que nos permite vislumbrar as relações de poder que envolvem professor, aluno e sociedade de acordo com cada época. Assim, é possível fazermos uma leitura das práticas disciplinares numa perspectiva processual e de longa duração, como é proposto pela teoria dos processos de civilização de Norbert Elias.

Ao agirem conforme um projeto maior atendendo aos interesses da época e do contexto, os professores possuem menores oportunidades de poder em relação ao Estado. Em relação aos estudantes, aqueles profissionais têm maiores oportunidades de poder, na maioria das vezes, dependendo-se do aspecto analisado. Docentes precisam ter um nível de conhecimento superior ao dos estudantes para acrescentarem e saberem conduzir as aulas suscitando aprendizagens. E, nesse caso, possuem um gradiente de poder maior que o do alunado.

No entanto, há situações em que o jogo se inverte e são os alunos que "podem" mais que os professores; um exemplo disso é quando estes deixam o lazer do final de semana para corrigir trabalhos dos estudantes. Outra ocasião em que é possível verificar o desequilíbrio de poder que circunda a figuração professor-aluno é a elaboração e o cumprimento das regras de boa convivência em sala de aula: ao serem solicitados a participarem dessa elaboração, os estudantes têm um maior gradiente de poder, mas, a obrigatoriedade de cumprimento dessas regras é fiscalizada pelo professor ou professora. Desse modo, embora discentes possam ter mais liberdade para expressar o que sentem e o que pensam, 
no final das contas, a balança de poder sempre pende para quem administra a dinâmica pedagógica: os professores e professoras.

Dito isso, veremos a seguir a importância que se deu ao papel disciplinador do professor na década de 1940, para contribuir na construção de uma sociedade renovada e em conformidade aos pressupostos da Escola Nova.

\section{A revista do ensino: pedagogia cultural a serviço do estado da Parahyba do Norte}

Orientando-se pela teoria processual de Elias (2008) é necessário voltar o olhar para as transformações das estruturas sociais e individuais de forma mútua, ou seja, considerar a interdependência entre elas e seus processos de mudança.

A Revista do Ensino, criada na Parahyba do Norte na década de 1930, patrocinada pelo Estado, tinha o intuito de instruir os professores primários da região acerca do novo ideário pedagógico constituído pelos pressupostos da Escola Nova. Além de divulgar as mudanças educacionais, a revista também propagava "[...] os feitos políticos do governo do Estado". (ASSUNÇÃO, 2016, p. 41)

De acordo com a literatura dos Estudos Culturais da Educação, pode-se dizer que a revista é uma pedagogia cultural por ser um artefato que educa os indivíduos, nesse caso, os leitores e leitoras docentes, como também pais e mães, sem explicitar os interesses que estão em jogo. Assim, a referida revista funcionou como um dispositivo cultural por transmitir valores e atitudes, estabelecendo um nível diferenciado de poder bastante direcionado aos professores. (WORTMAN; COSTA; SILVEIRA, 2015)

A primeira publicação da revista foi no ano de 1932, momento de mudanças renovadoras na educação brasileira. O perfil das publicações - conteúdo e layout - foram se transformando ao longo do tempo de acordo com as necessidades e ideias de cada época. A década de 1930 foi permeada pelo clima autoritário e patriótico, aspectos que estavam implícitas ou explicitamente presentes nas publicações da Revista, principalmente, nos artigos que objetivavam orientar os procedimentos dos professores e das professoras nos processos de ensino-aprendizagem.

A seguir, será analisado à luz da Teoria Eliasiana, o artigo "O problema da disciplina", publicado na última revista de número 18, no ano de 1942. Em relação a esse número, Assunção (2016) 
(1) Segundo Sena (2018) a maioria dos autores dos artigos da referida revista eram professores

incentivados ou mesmo

expressamente convocados pelo editorial da revista para contribuírem com suas produções pedagógicas voltadas para os problemas educativos. São professores de diferentes zonas que pertenciam a uma hierarquia no sistema de ensino do estado da Paraíba. Outros não era docentes, mas, sanitaristas, mencionados no sumário como doutores. José Benedito Salgado está indicado como professor. diz que o impresso incorpora em seus artigos o conceito de cultura, enfatizando-se os vieses educativo e cultural como forma de controle e censura.

\subsection{O problema da disciplina:a disciplina como estratégia de manutenção do poder}

O artigo "O problema da disciplina" tem como autoria o professor José Benedito Salgado. ${ }^{1}$ A tessitura do texto traz elementos históricos da prática reguladora de comportamentos no ambiente escolar, desde os castigos físicos até o uso de gestos simples, carregados de sanções implícitas.

O título do artigo transmite a mensagem da disciplina como um problema, porém, em seu decorrer, a utilização de práticas disciplinares apresenta-se como a ferramenta pedagógica mais propícia para lidar com os alunos, apesar da tarefa de disciplinar ser difícil e complexa para o professor, segundo o autor.

De acordo com a teoria processual de Elias (2008), a civilização é um processo contínuo, então, considerando-se a disciplina como prática civilizatória não há como estabelecer um ponto inicial da utilização da mesma na escola, pois, na lógica processual não há relação causal, as práticas não são delimitadas. Acredita-se aqui no ir e vir que move as figurações sociais e suas práticas em cada época e contexto.No início do texto, José Benedito Salgado (1942) diz que há duas maneiras de disciplinar a classe: por meio do "castigo físico" ou da "persuasão".

Acerca dos castigos físicos, afirma-se que é uma prática marcante na Escola Tradicional, deixada de lado, parcialmente, pela Escola Nova. Embora nesta, os castigos físicos tenham decaído, as punições continuaram acontecendo, mas de forma sutil, imbricadas em práticas disciplinares. Segundo o artigo, as punições físicas embotam a sensibilidade e a inteligência da criança, conforme o trecho: "O processo falseia o desenvolvimento da personalidade da criança, automatizando-a". (SALGADO, 1942) O autor ainda alerta que alunos fisicamente castigados podem se tornar "elementos rebeldes da sociedade" sendo alvos, certamente, de maiores e cruéis sanções. Tornam-se motivo de vergonha para todos em geral e, principalmente, para o professor. Ou seja, este é responsabilizado de forma direta, pelo tipo de sujeito que se pretende formar.

A vergonha, emoção que emerge das interações sociais, "é derivada do medo; medo da perda dos dois mais preciosos reconhecimentos 
da vida social, o respeito e a afeição". (GOUDSBLOM, 2009, p. 55) Nesse processo, a criança que não aprende a obedecer com seu professor, causa-lhe vergonha, podendo fazê-lo perder seu respeito perante a sociedade e, sobretudo, danificando sua autoridade enquanto docente.

Já a criança que é envergonhada pelo professor que tem a intenção discipliná-la, pode ter suas emoções reprimidas ou até mesmo converter a vergonha em raiva e, consequentemente, em comportamentos agressivos (GOUDSBLOM, 2009). Assim, de algum modo, situações de envergonhamento podem influenciar diretamente no desenvolvimento do autocontrole dos indivíduos. (ELIAS, 1990)

Em relação à segunda e defendida forma de disciplinar, a persuasão, evidencia-se que o "processo é de difícil aplicação e exige certa dose de inteligência" (SALGADO, 1942) por parte do professor. Há ainda referência aos estudos e contribuições da psicologia no fazer pedagógico, já que agora o centro do processo é o aluno.

Mesmo que nessa relação, os(as) estudantes sejam o centro e que seus interesses é que devem nortear, direcionar o processo, o professor permanece com maiores oportunidades de poder tendo-se em vista que permanece no centro do controle, responsável pelo processo de ensino-aprendizagem, sobretudo, pelo disciplinamento dos corpos do alunado. Em relação ao Estado, o docente permanece submisso e, de forma muitas vezes inconsciente, responsabiliza-se em grandes parcelas pelo "resultado" de seu trabalho.

Naquele momento, mais do que ensinar conteúdos conceituais, factuais e procedimentais, educar para a vida em sociedade por meio do ensino de conteúdos atitudinais que estivessem em consonância aos interesses daquela sociedade em mudança era a principal missão do educador. Desse modo, as práticas disciplinares têm a clara função regulatória de comportamentos para facilitar o ensino e, concomitante a isso, modelar cidadãos funcionando como excelente aparato de controle das emoções. (BRANDÃO, 2003) Nesse sentido, o professor deve ser simpático, entender os interesses da criança e, principalmente, disciplinar e ordenar esses interesses.

Apesar de assumir que não existem "regras aritméticas para a solução" (SALGADO, 1942) do problema da disciplina, o autor sugere alguns procedimentos que podem ser úteis. O primeiro deles é que o mestre deve se mostrar como autoridade e não como figura autoritária, como era recorrente na Escola Tradicional, desde 
os primeiros dias de aula, pois "o trabalho que tiver nessa ocasião The há de render ótimos frutos por todo o ano". (SALGADO, 1942)

É importante salientar que o poder permeia tanto a postura autoritária como a de autoridade. A diferença é que naquela, as oportunidades são extrapoladas havendo o abuso do poder por parte de quem ensina. Por outro lado, o docente que age por meio de sua autoridade tem maiores oportunidades de alcançar seus objetivos de ensino sem que seja preciso anular o outro no processo, nesse casto, os discentes.

Assim, esse posicionamento de autoridade está diretamente relacionado à lógica da persuasão, na qual, segundo o autor, está também relacionado ao carisma e estima que os estudantes desenvolvem pelo professor, o que o fazem respeitá-lo na dinâmica das aulas. Ou seja, comportar-se bem, ser disciplinado perante as ordens do professor na escola, que fazem parte das regras estabelecidas pela estrutura social, vai aos poucos transformando a estrutura individual dos alunos, promovendo-se o desenvolvimento do autocontrole, individualização/socialização de cada sujeito daquela figuração.

Sobre os processos de socialização de individualização, Elias (1990) afirma que ocorrem ao mesmo tempo, assim, no ambiente escolar, constrói-se a individualidade ao mesmo passo que se promove a socialização com outros indivíduos de diferentes culturas e formas de pensamento.

Noutro trecho, ressalta-se: quando for necessária a aplicação de sanções, o professor deve evitar colocar o(a)estudante para fora de imediato, pois o(a) mesmo(a) pode tornar a repetir condutas indisciplinadas. Deveria também evitar gritos e palavras impróprias, pois além de não educar, faz com que o professor perca o respeito. Numa passagem sobre como chamar a atenção, o Salgado (1942) descreve:

Como já disse, uma simples batida com um lápis na mêsa ou carteira, advertirão dos alunos que estiverem palestrando; uma breve pausa na explicação ou na leitura, indicará que alguém está atrapalhando os trabalhos.

O fragmento demonstra, mais uma vez, as maiores oportunidades de poder nas mãos do professor. Os pequenos gestos como bater com lápis noutros objetos - não mais nos alunos, como na escola tradicional - e silenciar quando interrompido, corroboram o 
poder do simbólico nas práticas que se enraizaram e perduram até os dias atuais. No decorrer do processo educativo no ambiente escolar, as crianças vão internalizando saberes e regras, apropriando-se do habitus social, que para Elias (1994) corresponde à composição social dos indivíduos.

Em casos de pequenas ocorrências, como o desaparecimento de objetos, é sinalizado que o professor deve promover uma pequena sindicância e, caso o culpado não apareça, pelo menos ficará assustado não voltando a fazê-lo. A descrição desse tipo de situação corrobora o ideal escolonovista da escola como uma microssociedade: roubar ou furtar são atos criminosos que possuem consequências, isso se aprende na escola, haja vista que é nela que se aprende a viver em sociedade.

Observa-se de forma clara a figuração estabelecidos-outsiders na relação professor-aluno. O professor, um bom modelo social a ser seguido, faz parte do grupo dos estabelecidos; enquanto os estudantes, são considerados outsiders, aqueles que transgridem as regras, sendo vistos como inferiores em relação aos estabelecidos. (ELIAS; SCOTSON, 2000)

Outra proposta do autor diz respeito ao ato de sorrir com a classe, mas com o cuidado de não provocar anarquia entre os alunos. Os sorrisos também devem ser controlados pelo docente, silenciando-os ao simples gesto da autoridade. Também é conveniente contar histórias que tenham um ensinamento moral e sirvam como atrativo aos alunos, conforme o trecho:

Em lugar de admoestar, peça-lhes, querendo, que façam silêncio para ouvir uma bela história, e todos ficam como que automaticamente atentos, habituando-se insensivelmente á disciplina, á ordem que necessariamente deve reinar em uma escola. Se as histórias tiverem fundo moral ou cívico, constituirão ademais, belas lições de uma matéria muito descurada por certos mestres: a Instrução Moral e Cívica. (SALGADO, 1942)

Ao afirmar que os conteúdos relacionados à disciplina de Instrução Moral e Cívica que, apesar de ser descurada por alguns mestres significam "belas lições", representa o reflexo do período ditatorial e repressor que circundava o país naquele momento, o Estado Novo. 
O civismo, o amor e devoção à pátria, era um dos pilares da educação, por meio da inculcação de valores que manteriam o equilíbrio social.Nesse sentido, fica clara a rede de interdependência entre a escola e o Estado: as práticas disciplinares que constituíam a escola eram representadas numa linguagem patriótica e intencional no sentido de construir e manter o Estado da Parayba do Norte no perfil exigido pela nação.

Salgado também ressalta a importância do professor estar atento e nunca perder a classe de vista, além de ter muito cuidado com os gestos e "a pronúncia do ' $r$ ' e do 'l'..." (SALGADO, 1942), ou seja, os erros são inadmissíveis. Daí, pode-se inferir que: os professores não poderiam errar diante de seus alunos, pois além de danificar sua autoridade de quem sabe, também seria o oferecimento de um modelo inadequado que poderia ser reproduzido pela turma.

O artigo é concluído expressando-se a importância do professor saber se prevenir, pois, a falta da disciplina na classe, poderia pôr em risco o prestígio que esse profissional deve ter na escola e fora dela. Acentua-se, portanto, a figura do professor como modelo a ser seguido pelos alunos sem questionamentos (figuração estabelecidos-outsiders).

\section{Considerações finais}

A análise do artigo "O problema da disciplina" permitiu vislumbrar a indissociável relação estabelecida entre a escola e a sociedade. A configuração escolar em sua função civilizatória é palco de conflitos sociais, culturais e políticos, sendo assim, a prática pedagógica dos professores revela-se como complexa e permeada de diferentes interesses.

Fazer a leitura de como era conveniente aos docentes procederem em relação a disciplinarização dos estudantes à luz da Teoria do Processos de Norbert Elias, possibilitou a compreensão das relações de poder que "equilibram" a educação numa perspectiva processual, ou seja, sem haver necessariamente uma relação causal, mas uma dimensão de continuidade, de interdependência entre as ações dos sujeitos que constituem diferentes configurações sociais.

A tese do artigo analisado era de que a persuasão era a melhor forma do professor disciplinar, em detrimento dos castigos físicos recorrentes na proposta tradicional de ensino. Mas persuadir em 
relação a quê? Persuadir os estudantes de que o modelo social personificados nos professores era o melhor a ser seguido.

Desse modo, verificou-se que os jogos de poder que permeiam a figuração professor-aluno favorecem sempre o professor em seu claro papel de modelador de comportamentos socialmente aceitáveis tanto em sala de aula como fora dos muros da instituição escolar. Destarte, o artigo explicita a intencionalidade das práticas pedagógicas favorecidas pelas grandes oportunidades de poder docente: formar cidadãos civilizados, o que naquela época significava a valorização e o respeito a pátria.

Se já não se optava pelo castigo físico, "persuadir" era a tarefa maior do professor, mas o seu poder e sua centralidade no processo não estavam em questionamento. No entanto, castigando ou persuadindo, o foco continuou sendo naquele profissional e em sua prática pedagógica, principalmente, no que diz respeito à regulação do comportamento das crianças.

Destarte, por meio de gestos e procedimentos sutis, as práticas disciplinares atuam a favor do controle das emoções. A regulação externa por parte do professor dentro da estrutura social escolar desencadeia a autorregulação ou autocontrole dos estudantes, um dos aspectos centrais do que foi colocado por Norbert Elias como processo civilizador, controle social e individual das emoções, preparando-os para a vida em sociedade.

Naquele momento, as práticas, os conteúdos e os ensinamentos disseminados na Revista do Ensino no estado da Parahyba do Norte, contribuíram de forma clara e direta, para o progresso daquele estado em relação a nova cultura que permeava o país na década de 40. Portanto, por meio da perspectiva processual e sociológica da Teoria Eliasiana, o pressente estudo possibilitou a reflexão de que muitas das propostas do artigo analisado perduram até os dias atuais, manifestando-se de diferentes formas com diferentes nomes e/ou abordagens pedagógicas, mas sempre com intuito de educar ou modelar os corpos para que se tornem socialmente funcionais.

\section{The school discipline in the 1940's: aspects of the interdependence between School and State}

\footnotetext{
Abstract: The disciplinary practices presented in the article "The problem of discipline" published in the Revista do Ensino, in the 1940s, were analyzed in the light of Norbert Elias's Theory of Processes. It is a study with a qualitative approach performed through a documentary analysis. A brief discussion was
} 
made of changes in teacher behavior in relation to student behavior: from physical punishment to persuasion strategies through disciplinary strategies. This magazine was understood as a cultural pedagogy, having in mind that it educated teachers of that time and context. The analysis developed from the point of view of Eliasian theory allowed us to glimpse the practices and power games that surround teacher-student figuration and, above all, the commitment of school education to the State in the formation of civilized citizens and citizens. Punishing or persuading, the focus continued to be the teacher and his pedagogical practice, mainly, with respect to the regulation of the children's behavior.

Keywords: Education. Disciplinary practices. Theory of Processes. Teacher-student figuration.

\title{
La disciplina escolar enla décadade 1940: aspectos de la interdependencia entre la Escuela y el Estado
}

\begin{abstract}
Resumen: Se analizaron las prácticas disciplinarias presentes en el artículo "El problema de la disciplina" publicado en la Revista de la Enseñanza, en la década del 1940, a la luz de la Teoría de los Procesos de Norbert Elias. Se trata de um estudio con enfoque cualitativo realizado por medio de um análisis documental. Se hizo una breve discusión acerca de los cambios de conducta docente en relación al comportamiento discente: de los castigos físicos a las estrategias de persuasión, por medio de las estrategias disciplinarias. Se comprendió la referida revista como una pedagogía cultural, teniendo en vista que educaba docentes de aquella época y contexto. El analisis que se desarrolló bajo la óptica de la Teoria Eliasiana permitió vislumbrar las prácticas y los juegos de poder que circundan la figuración profesor-alumno y, principalmente, el compromiso de la educación escolar con el Estado em la formación de ciudadanas y ciudadanos civilizados. Castigando o persuadiendo, el foco continuó siendo el profesor y supráctica pedagógica, principalmente, en lo que se refiere a la regulación del comportamiento de los niños.
\end{abstract}

Palabras clave: Educación. Prácticas disciplinarias. Teoría de los Procesos. Figuración profesor-alumno.

\section{Referências}

ASSUNÇÃO, Albanisa Maria de. Primaveras de destinos na Revista do Ensino no Estado da Paraíba. As prescrições na História da Educação e as representações do ensino de história (1932 a 1942). 2016. Dissertação (Mestrado em Educação) - Universidade Federal da Paraîba, João Pessoa: Paraíba, 2016.

BRANDÃO, Carlos da Fonseca. Norbert Elias: formação, educação e emoções no processo de civilização. Petrópolis, RJ: Vozes, 2003.

ELIAS, Norbert. O processo civilizador: uma história dos costumes. Rio de Janeiro: Zahar, 1990.

ELIAS, Norbert. A sociedade dos indivíduos. Rio de Janeiro: Jorge Zahar, 1994.

ELIAS, Norbert. Introdução à sociologia. Lisboa: Edição 70, 2008. 
ELIAS, Norbert.A civilização dos pais. Sociedade e estado, Brasília, DF, v. 27, n. 3, p. 469-493, 2012. Disponível em: www.scielo.br/scielo. php? script $=$ sci_arttext\&pid $=$ S0102-69922012000300003. Acesso em: 5 abr. 2018.

ELIAS, Norbert; SCOTSON, John. Os estabelecidos e os outsiders: sociologia das relações de poder a partir de uma pequena comunidade. Rio de Janeiro: Jorge Zahar, 2000.

GOUDSBLOM, Johan. A vergonha: uma dor social. In: GEBARA; Ademir; WOUETRS, Cas. (org.). O controle das emoções. João Pessoa: Editora Universitária da UFPB, 2009. p.47-60.

SALGADO, José Benedito. O problema da disciplina. Revista do ensino,João Pessoa, Ano X, n. 18, mmaio/ jun., jul., 1942.

SENA, Fabiana. A escrita de professores na Revista do Ensino da Paraíba (1932-1942) como um projeto de nação. In: NERY, Ana Clara Bortoleto; GONDRA, José (org.). Imprensa pedagógica na ibero-américa: local, nacional e transnacional. São Paulo: Alameda, 2018. v. 1, p. 1-524.

SOUZA, Rita de Cássia de. Punições e disciplina: introdução ao estudo da cultura escolar. In: CONGRESSO DE PESQUISA E ENSINO EM HISTÓRIA DA EDUCAÇÃO EM MINAS GERAIS, 2003, Uberlândia. Anais [...], Uberlândia: Universidade Federal de Uberlândia, 2003. Disponível em: http://www2.faced.ufu.br/nephe/images/arq-indnome/eixo7/completos/punicoes-disciplina.pdf. Acesso em: 26 abr. 2018.

VINCENT, Guy; LAHIRE, Bernard; THIN, Daniel. Sobre a história e a teoria da forma escolar. Educação em Revista, Belo Horizonte, n. 33, p. 7-47, jun. 2001. Disponível em: http://www.piraquara.pr.gov.br/ aprefeitura/secretariaseorgaos/educacao/uploadAddress/Sobre_a_ histu00F3ria_e_a_teoria_da_forma_escolar\%5B1273\%5D.pdf. Acesso em: 10 abr. 2018.

WORTMANN, Maria Lúcia; COSTA, Marisa Vorraber; SILVEIRA, Rosa Hessel. Sobre a emergência e a expansão dos Estudos Culturais em Educação no Brasil. Educação, Porto Alegre, v. 38, n. 1, p. 32-48, jan./abr. 2015. Disponível em: http://revistaseletronicas.pucrs.br/ojs/ index.php/faced/article/view/18441/0. Acesso em: 10 jun. 2018.

Submetido em: 15/04/2019

Aceito em: 18/09/2019 